\title{
A FUSION OF SOFT EXPERT SET AND MATRIX MODELS
}

\author{
A.Arokia Lancy ${ }^{1}$, I. Arockiarani ${ }^{2}$ \\ ${ }^{1}$ Research Scholar, ${ }^{2}$ Research Supervisor, Department of Mathematics, Nirmala College for Women Coimbatore, India, \\ aarokia.lancy@gmail.com
}

\begin{abstract}
The purpose of this paper is to define different types of matrices in the light of soft expert sets. We then propose a decision making model based on soft expert set.
\end{abstract}

Keywords: Soft set, soft expert set, Soft Expert matrix.

\section{INTRODUCTION}

In 1999, Molodtsov [8] initiated the theory of soft set, after a detailed analysis of inherent difficulties for dealing with uncertainty and incompleteness of information. He proposed soft set theory which contains sufficient parameters to overcome the difficulties which exist in interval analysis, fuzzy set theory and so on. In 2003 Maji et al. [5], proposed several operations on soft sets. In 2005, Pei and Miao[9] and Chen[2] improved the work of Maji et al. These work geared up research in the field of soft sets.

Fuzzy soft set which is a combination of Fuzzy set and soft set was first introduced by Maji et al. [3], in the year 2001.All these research aim to solve most of our real life problems in medical sciences, engineering, management, environment and social sciences which involve data that are not crisp and precise. Moreover all the models created will deal only with one expert. To redefine this one expert opinion, Alkhazaleh and Salleh in 2011 [1] developed the theory of soft expert set in which the user can know the opinion of all experts which is more effective in making very crucial decisions.

Matrices play an important role in the broad area of science and engineering. Yong et al [11] introduced a matrix representation of a fuzzy soft set and Borah et al [6] extended fuzzy soft matrix theory and gave some examples.

In this paper a new dimension is given to the soft expert set through matrices to solve a decision making problem.

\section{PRELIMINARIES}

Let $U$ be a universe, $E$ a set of parameters and $X$ a set of experts (agents). Let $\mathrm{O}$ be a set of opinions, $\mathrm{Z}=\mathrm{E} \times \mathrm{X} \times \mathrm{O}$ and $\mathrm{A} \subseteq \mathrm{Z}$.

\subsection{Definition [1]}

A pair $(F, A)$ is called a soft expert set over $U$, where $F$ is a mapping given by $\mathrm{F}: \mathrm{A} \rightarrow \mathrm{P}(\mathrm{U})$, where $\mathrm{P}(\mathrm{U})$ denote the power set of U.

\subsection{Definition [1]}

For two soft expert sets $(\mathrm{F}, \mathrm{A})$ and $(\mathrm{G}, \mathrm{B})$ over $\mathrm{U},(\mathrm{F}, \mathrm{A})$ is called a soft expert subset of $(\mathrm{G}, \mathrm{B})$ if (i) $\mathrm{A} \subseteq \mathrm{B}$ (ii) for all

$\mathrm{e} \in \mathrm{A}, \quad \mathrm{F}(\mathrm{e}) \subseteq \mathrm{G}(\mathrm{e})$. This relationship is denoted by (F,A) $\subseteq$ $(\mathrm{G}, \mathrm{B})$. In this case $(\mathrm{G}, \mathrm{B})$ is called the soft expert super set of $(\mathrm{F}, \mathrm{A})$.

\subsection{Definition [1]}

Two soft expert sets $(F, A)$ and $(G, B)$ over $U$ are said to be equal if $(F, A)$ is soft expert subset of $(G, B)$ and $(G, B)$ is called a soft expert subset of (F,A).

\subsection{Definition [1]}

Let $E$ be a set of parameters and $X$, a set of experts The NOT set of $Z=E \times X \times$ O denoted by $\neg Z$, is defined by $\neg Z=\{$ $\left.\left(\neg \mathrm{e}_{\mathrm{i}}, \mathrm{x}_{\mathrm{j}}, \mathrm{o}_{\mathrm{k}}\right) \forall \mathrm{i}, \mathrm{j}, \mathrm{k}\right\}$ where $\neg \mathrm{e}_{\mathrm{i} \text { is not }} \mathrm{e}_{\mathrm{i}}$.

\subsection{Definition [1]}

The complement of a soft expert set $(\mathrm{F}, \mathrm{A})$ is denoted by $(\mathrm{F}, \mathrm{A}) \mathrm{c}$ and is defined by

$(\mathrm{F}, \mathrm{A}) \mathrm{c}=(\mathrm{Fc}, \neg \mathrm{A})$

where $\mathrm{Fc}: \neg \mathrm{A} \rightarrow \mathrm{P}(\mathrm{U})$ is a mapping given by $\mathrm{Fc}(\mathrm{e})=\mathrm{U}-$ $\mathrm{F}(\mathrm{e}), \forall \mathrm{e} \in \neg \mathrm{A}$ 


\subsection{Definition [1]}

An agree- soft expert set $(\mathrm{F}, \mathrm{A})_{1}$, over $\mathrm{U}$ is a soft expert subset of (F,A) defined as $(\mathrm{F}, \mathrm{A})_{1}=\left\{\mathrm{F}_{1}(\mathrm{e}): \mathrm{e} \in \operatorname{ExXx}\{1\}\right\}$.

\subsection{Definition [1]}

An disagree- soft expert set $(\mathrm{F}, \mathrm{A})_{0}$, over $\mathrm{U}$ is a soft expert subset of $(\mathrm{F}, \mathrm{A})$ defined as $(\mathrm{F}, \mathrm{A})_{0}=\left\{\mathrm{F}_{0}(\mathrm{e}): \mathrm{e} \in \operatorname{ExXx}\{0\}\right\}$

\subsection{Definition [1]}

The union of two soft expert sets of (F, A) and (G, B) over U

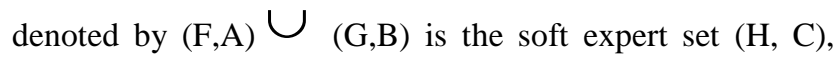
where $\mathrm{C}=\mathrm{A} \cup \mathrm{B}$ and for all

$$
\begin{aligned}
& \mathrm{e} \in \mathrm{C}, \mathrm{H}(\mathrm{e})=\mathrm{F}(\mathrm{e}) \text { if } \mathrm{e} \in \mathrm{A}-\mathrm{B}, \mathrm{G}(\mathrm{e}) \text { if } \\
& \mathrm{e} \in \mathrm{B}-\mathrm{A} \text { and } \mathrm{F}(\mathrm{e}) \cup \mathrm{G}(\mathrm{e}) \text { if } \mathrm{e} \in \mathrm{A} \cap \mathrm{B} .
\end{aligned}
$$

\subsection{Definition [1]}

The intersection $(\mathrm{H}, \mathrm{C})$ of two soft expert sets $(\mathrm{F}, \mathrm{A})$ and $(\mathrm{G}$,

B) over a common universe $\mathrm{U}$, denoted (F, A) $\cap$ (G, B), is defined as $\quad \mathrm{C}=\mathrm{A} \cap \mathrm{B}$, and for all $\mathrm{e} \in \mathrm{C}, \mathrm{H}(\mathrm{e})=\mathrm{F}(\mathrm{e})$ if e $\in A-B, G(e)$ if $e \in B-A$ and $\quad F(e) \cap \mathrm{G}(e)$ if $e$ $\in \mathrm{A} \cap \mathrm{B}$.

\subsection{Definition [1]}

If $(\mathrm{F}, \mathrm{A})$ and $(\mathrm{G}, \mathrm{B})$ are two soft expert sets over $\mathrm{U}$, then $(\mathrm{F}, \mathrm{A})$

$$
(F, A) \vee(G, B)=(O, A x B)
$$

$$
\text { where } O(\alpha, \beta)=F(\alpha) \tilde{\cup} G(\beta),
$$

$\mathrm{OR}(\mathrm{G}, \mathrm{B})$ is defined as $\forall(\alpha, \beta) \in A x B$.

\subsection{Definition [7]}

A pair $(\mathrm{F}, \mathrm{A}) \mathrm{D}$ is called a fuzzy parameterized soft expert set (FPSES) over $\mathrm{U}$, where $\mathrm{F}$ is a mapping given by FD : A $\rightarrow$ $\mathrm{P}(\mathrm{U})$, and $\mathrm{P}(\mathrm{U})$ denotes the power set of $\mathrm{U}$.

\subsection{Definition [6]}

Let $\mathrm{U}=\{\mathrm{c} 1, \mathrm{c} 2, \ldots \mathrm{cm}\}$ be the universal set and $\mathrm{E}$ be the set of parameters given by $\mathrm{E}=\{\mathrm{e} 1, \mathrm{e} 2, \ldots . \mathrm{en}\}$. Let $\mathrm{A} \subseteq \mathrm{E}$ and $(\mathrm{F}, \mathrm{A})$ be a fuzzy soft set in the fuzzy soft class (U,E). Then fuzzy soft set $(\mathrm{F}, \mathrm{A})$ in a matrix form as
$A_{m \times n}=\left\lfloor a_{i j}\right\rfloor$ or $A=\left\lfloor a_{i j}\right\rfloor, \mathrm{i}=1,2, \ldots \ldots \mathrm{m}$

$\mathrm{j}=1,2, \ldots . . \mathrm{n}$

where $a_{i j}=\left\{\begin{array}{ll}\mu_{j}\left(c_{i}\right) & \text { if } e_{j} \in A \\ 0 & \text { if } e_{j} \notin A\end{array}\right\}$

$\mu_{j}\left(c_{i}\right)$ reprent th e membership of $c_{i}$ in the

fuzzy set $\mathrm{F}\left(e_{j}\right)$

\subsection{Definition [10]}

Let $U=\{\mathrm{c} 1, \mathrm{c} 2, \ldots . \mathrm{cm}\}$ be the universal set and $\mathrm{E}$ be the set of parameters given by

$$
\mathrm{E}=\{\mathrm{e} 1, \mathrm{e} 2, \quad \mathrm{en}\} .
$$

Let $\mathrm{A} \subseteq \mathrm{E}$ and $(\mathrm{F}, \mathrm{A})$ be a intuitionistic fuzzy soft set in the fuzzy soft class (U,E). Then intuitionistic fuzzy soft set (F,A) in a matrix form as

$$
\begin{aligned}
& A_{m \times n}=\left\lfloor a_{i j}\right\rfloor \text { or } A=\left\lfloor a_{i j}\right\rfloor, \\
& \mathrm{i}=1,2, \ldots \ldots \mathrm{m} \quad \mathrm{j}=1,2, \ldots \ldots \mathrm{n}
\end{aligned}
$$

where $a_{i j}=\left\{\begin{array}{ll}\left(\mu_{j}\left(c_{i}\right), v_{j}\left(c_{i}\right)\right) & \text { if } e_{j} \in A \\ (0,1) & \text { if } e_{j} \notin A\end{array}\right\}$

$\mu_{j}\left(c_{i}\right)$ represent the membership of $c_{i}$

in the intuitionistic fuzzy set $\mathrm{F}\left(e_{j}\right)$

$v_{j}\left(c_{i}\right)$ represent the non-membership of $c_{i}$ in the intuitionistic fuzzy set $\mathrm{F}\left(e_{j}\right)$

\subsection{Definition [10]}

Let $A=\left\lfloor a_{i j}\right\rfloor \in \operatorname{IFSM}_{\mathrm{m} \times \mathrm{n}}$, where $a_{i j}=\left(\mu_{j}\left(c_{i}\right), v_{j}\left(c_{i}\right)\right)$.

Then the value matrix of intuitionistic fuzzy soft matrix $\mathrm{A}$ is $\mathrm{V}(\mathrm{A})=\left[a_{i j}\right]=\left[\mu_{j}\left(c_{i}\right)-v_{j}\left(c_{i}\right)\right]$, $\mathrm{i}=1,2, \ldots \mathrm{m} \mathrm{j}=1,2, \ldots . \mathrm{n}$

\subsection{Definition [10]}

Let $A=\left\lfloor a_{i j}\right\rfloor \in \operatorname{IFSM}_{\mathrm{m} \times \mathrm{n}}, B=\left\lfloor b_{i j}\right\rfloor \in \mathrm{IFSM}_{\mathrm{m} \times \mathrm{n}}$, then we define score matrix of $\mathrm{A}$ and $\mathrm{B}$ as $\mathrm{S}_{(\mathrm{A}, \mathrm{B})}=\left[d_{i j}\right]$ where $d_{i j}=\mathrm{V}(\mathrm{A})-\mathrm{V}(\mathrm{B})$. 


\subsection{Definition [10]}

Let $A=\left\lfloor a_{i j}\right\rfloor \in \mathrm{IFSM}_{\mathrm{m} \times \mathrm{n}}, B=\left\lfloor b_{i j}\right\rfloor \in \mathrm{IFSM}_{\mathrm{m} \times \mathrm{n}}$.

Let the correspond ing value matrices be $\mathrm{V}(\mathrm{A}), \mathrm{V}(\mathrm{B})$ and their score matrix is $\mathrm{S}_{(\mathrm{A}, \mathrm{B})}=\left[d_{i j}\right]_{m \times n}$, then the Total Score for each $\mathrm{c}_{\mathrm{i}}$ in $\mathrm{U}$ is $\mathrm{S}_{\mathrm{i}}=\sum_{j=1}^{n} d_{i j}$

\section{SOFT EXPERT MATRIX}

\subsection{Definition}

Let $\mathrm{U}=\left\{\mathrm{u}_{1}, \mathrm{u}_{2}, \mathrm{u}_{3}\right\}$ be a universe, $\mathrm{E}$ a set of parameters is given by $E=\left\{e_{1}, e_{2}, \ldots . e_{n}\right\}$ and $X$ a set of experts (agents). Let $O$ be a set of opinions, $\mathrm{Z}=\mathrm{E} \times \mathrm{X} \times \mathrm{O}$ and $\mathrm{A} \subseteq \mathrm{Z}$. Then then the matrix representation of the soft expert set over $(F, A)$ is defined as

$A_{m \times n}=\left\lfloor a_{i j}\right\rfloor$ or $A=\left\lfloor a_{i j}\right\rfloor$,

$\mathrm{i}=1,2, \ldots \ldots \mathrm{m} \quad \mathrm{j}=1,2, \ldots . \mathrm{n}$

where $a_{i j}=\left\{\begin{array}{ll}\left(a g_{j}\left(u_{i}\right), d g_{j}\left(u_{i}\right)\right) & \text { if } e_{j} \in A \\ (0,1) & \text { if } e_{j} \notin A\end{array}\right\}$

$a g_{j}\left(u_{i}\right)$ represent the level of acceptance of $u_{i}$

in the soft expert set $\mathrm{F}\left(e_{j}\right)$

$d g_{j}\left(c_{i}\right)$ represent the level non - acceptance of $u_{i}$

in the soft expert set $\mathrm{F}\left(e_{j}\right)$

\subsection{Definition}

\section{Soft Expert Equal Matrix:}

Let $A=\left[a_{i j}\right]$ and $\mathrm{B}=\left[\mathrm{b}_{\mathrm{ij}}\right]$

be two expert matrices, then $\mathrm{A}$ is equal to $\mathrm{B}$ if

$a g_{A}=a g_{B}$ and $d g_{A}=d g_{B} \forall \mathrm{i}, \mathrm{j}$.

\subsection{Definition}

\section{Soft Expert Complement Matrix:}

$A=\left[a_{i j}\right]$ be a soft expert matrix,

where $a_{i j}=\left(a g_{j}\left(u_{i}\right), d g_{j}\left(u_{i}\right)\right)$.

Then the complement of the soft expert matrix is

denoted by $A^{c}=\left[a_{i j}{ }^{c}\right]$

where $a_{i j}{ }^{c}=\left(d g_{j}\left(u_{i}\right), a g_{j}\left(u_{i}\right)\right) \forall \mathrm{i}, \mathrm{j}$.

\subsection{Definition}

\section{Addition of Two Soft Expert Matrices:}

Let $A=\left[a_{i j}\right]_{\mathrm{mxn}}$ and $\mathrm{B}=\left[\mathrm{b}_{\mathrm{ij}}\right]_{\mathrm{mxn}}$ be two expert matrices, then we define addition of $\mathrm{A}$ and $\mathrm{B}$ as $A+B=\left\lfloor c_{i j}\right\rfloor_{m x n}=\left(\max \left(a g_{A}, a g_{B}\right), \min \left(d g_{A}, d g_{B}\right)\right) \forall \mathrm{i}, \mathrm{j}$.

\subsection{Definition}

\section{Subtraction of Two Soft Expert Matrices:}

Let $A=\left[a_{i j}\right]_{\mathrm{mxn}}$ and $\mathrm{B}=\left[\mathrm{b}_{\mathrm{ij}}\right]_{\mathrm{mxn}}$ be two expert matrices, then we define subtraction of $\mathrm{A}$ and $\mathrm{B}$ as $A-B=\left\lfloor c_{i j}\right\rfloor_{m x n}=\left(\min \left(a g_{A}, a g_{B}\right), \max \left(d g_{A}, d g_{B}\right)\right)$ $\forall \mathrm{i}, \mathrm{j}$.

\subsection{Definition}

\section{Product of Two Soft Expert Matrices:}

Let $A=\left[a_{i j}\right]_{\mathrm{mxn}}$ and $\mathrm{B}=\left[\mathrm{b}_{\mathrm{ij}}\right]_{\mathrm{nxp}}$ be two expert matrices, then we define product of $\mathrm{A}$ and $\mathrm{B}$ as $A^{*} B=\left[c_{i k}\right]_{m x p}=\left(\operatorname{maxmin}\left(a g_{A j}, a g_{B j}\right), \operatorname{minmax}\left(d g_{A j}, d g_{B j}\right)\right) \forall \mathrm{i}, \mathrm{j}$.

\subsection{Proposition}

1. $A+B=B+A$ 2. $A-B=B-A$ 3. $A * B \neq B * A$ 4. $A+I=A$ Proof: It follows from the definition.

\subsection{Example}

Let

$$
\begin{aligned}
& A=\left(\begin{array}{ll}
(0.2,0.3) & (0.1,0.3) \\
(0.5,0.3) & (0.6,0.4)
\end{array}\right), B=\left(\begin{array}{cc}
(0.7,0.5) & (0.3,0.1) \\
(0.1,0) & (0.1,0.1)
\end{array}\right) \\
& \text { Then A + B }=\left(\begin{array}{cc}
(0.7,0.3) & (0.3,0.1) \\
(0.5,0) & (0.6,0.1)
\end{array}\right) \\
& \mathrm{A}-\mathrm{B}=\left(\begin{array}{ll}
(0.2,0.5) & (0.1,0.3) \\
(0.1,0.3) & (0.1,0.4)
\end{array}\right) \\
& \mathrm{A} * \mathrm{~B}=\left(\begin{array}{ll}
(0.2,0.3) & (0.2,0.3) \\
(0.5,0.4) & (0.3,0.3)
\end{array}\right)
\end{aligned}
$$

\section{AN APPLICATION OF SOFT EXPERT SET} USING MATRIX MODEL

Suppose that a manufacturing firm wants to set up its processing unit and suppose there are three different locations under consideration to set up the unit. The manufacturing firm wants a committee of experts $\{\mathrm{p}, \mathrm{q}\}$ to study the location based on some parameters and to give their opinion of the best 
choice of location so that the loss in time, energy, men and material will be minimized.

Let $U=\left\{u_{1}, u_{2}, u_{3}\right\}$ be the set of locations, let $\left\{e_{1}, e_{2}, e_{3}\right\}$ denote the parameters such as availability of raw materials, availability of labour, frequent transport facility.

After a detailed analysis the expert committee gives its opinion as follows

$(\mathrm{F}, \mathrm{Z})=\left\{\left\{\left(\mathrm{e}_{1}, \mathrm{p}, 1\right)\left\{\left(\mathrm{u}_{1} / 0.3\right),\left(\quad \mathrm{u}_{2} / 0.2\right),\left(\quad \mathrm{u}_{3} / 0.3\right)\right\}\right\}\right.$, $\left\{\left(\mathrm{e}_{2}, \mathrm{p}, 1\right)\left\{\left(\mathrm{u}_{1} / 0.3\right),\left(\mathrm{u}_{2} / 0.4\right),\left(\mathrm{u}_{3} / 0.3\right)\right\}\right\}$,

$\left\{\left(\mathrm{e}_{3}, \mathrm{p}, 1\right)\left\{\left(\mathrm{u}_{1} / 0.1\right),\left(\mathrm{u}_{2} / 0.4\right),\left(\mathrm{u}_{3} / 0.5\right)\right\}\right\}, \quad\left\{\left(\mathrm{e}_{1}, \mathrm{q}, 1\right)\left\{\left(\mathrm{u}_{1} / 0.1\right),(\right.\right.$ $\left.\left.\left.\mathrm{u}_{2} / 0\right),\left(\mathrm{u}_{3} / 0.2\right)\right\}\right\}$,

$\left\{\left(\mathrm{e}_{2}, \mathrm{q}, 1\right)\left\{\left(\mathrm{u}_{1} / 0.1\right),\left(\mathrm{u}_{2} / 0.5\right),\left(\mathrm{u}_{3} / 0.1\right)\right\}\right\},\left\{\left(\mathrm{e}_{3}, \mathrm{q}, 1\right)\left\{\left(\mathrm{u}_{1} / 0\right),\left(\mathrm{u}_{2} / 0\right),(\right.\right.$ $\left.\left.\left.\mathrm{u}_{3} / 0.1\right)\right\}\right\}$,

$\left\{\left(\mathrm{e}_{1}, \mathrm{p}, 0\right)\left\{\left(\mathrm{u}_{1} / 0.2\right),\left(\mathrm{u}_{2} / 0.3\right),\left(\mathrm{u}_{3} / 0.1\right)\right\}\right\}, \quad\left\{\left(\mathrm{e}_{2}, \mathrm{p}, 0\right)\left\{\left(\mathrm{u}_{1} / 0.5\right),(\right.\right.$ $\left.\left.\left.\mathrm{u}_{2} / 0.5\right),\left(\mathrm{u}_{3} / 0.1\right)\right\}\right\}$,

$\left\{\left(\mathrm{e}_{3}, \mathrm{p}, 0\right)\left\{\left(\mathrm{u}_{1} / 0.2\right),\left(\mathrm{u}_{2} / 0.3\right),\left(\mathrm{u}_{3} / 0.1\right)\right\}\right\}, \quad\left\{\left(\mathrm{e}_{1}, \mathrm{q}, 0\right)\left\{\left(\mathrm{u}_{1} / 0.3\right),(\right.\right.$ $\left.\left.\left.\mathrm{u}_{2} / 0.5\right),\left(\mathrm{u}_{3} / 0.3\right)\right\}\right\}$,

$\left\{\left(\mathrm{e}_{2}, \mathrm{q}, 0\right)\left\{\left(\mathrm{u}_{1} / 0.3\right),\left(\mathrm{u}_{2} / 0.7\right),\left(\mathrm{u}_{3} / 0.3\right)\right\}\right\}, \quad\left\{\left(\mathrm{e}_{3}, \mathrm{q}, 0\right)\left\{\left(\mathrm{u}_{1} / 0.1\right),(\right.\right.$ $\left.\left.\left.\left.\mathrm{u}_{2} / 0.1\right),\left(\mathrm{u}_{3} / 0.1\right)\right\}\right\}\right\}$

The following matrices A and B confines the data given by the experts $\mathrm{p}$ and $\mathrm{q}$ respectively

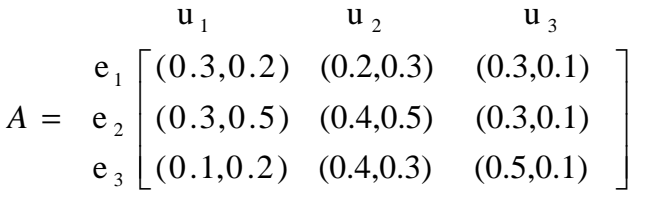

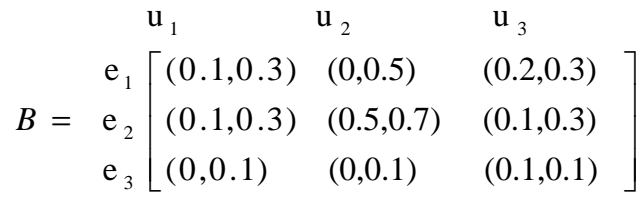

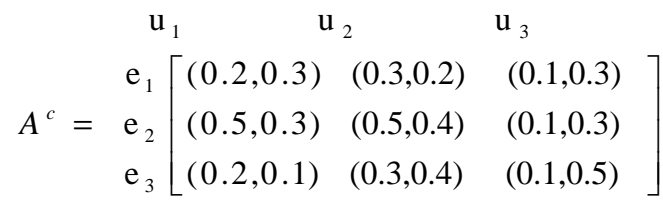

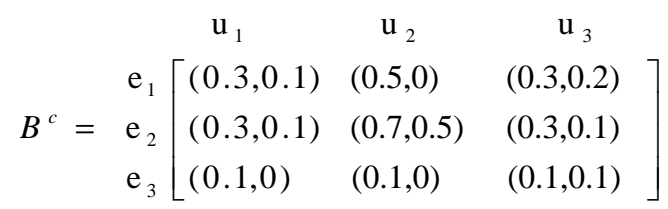

The operation of addition of two matrices are carried out, then the value of the added matrix is found to be

$$
\begin{gathered}
V(A+B)=\left[\begin{array}{ccc}
0.1 & -0.1 & 0.2 \\
0 & 0 & 0.2 \\
0 & 0.3 & 0.4
\end{array}\right] \\
V\left(A^{c}+B^{c}\right)=\left[\begin{array}{llr}
0.2 & 0.5 & 0.1 \\
0.4 & 0.3 & 0.2 \\
0.2 & 0.3 & 0
\end{array}\right]
\end{gathered}
$$

$V(A+B)-V\left(A^{c}+B^{c}\right)=\left[\begin{array}{ccl}-0.1 & -0.6 & 0.1 \\ -0.4 & -0.3 & 0 \\ -0.2 & 0 & 0.4\end{array}\right]$

The score for $\mathrm{u}_{1}=-0.1-0.4-0.2=-0.7$

The score for $\mathrm{u}_{2}=-0.6-0.3+0=-0.9$

The score for $\mathrm{u}_{3}=0.1+0+0.4=0.5$

From the above scores the manufacturing firm will select the location with the highest score $\left(\mathrm{u}_{3}\right)$.

\section{CONCLUSIONS}

An efficient decision making saves time, labour and economy. If the decisive parameters are given proper attention, according to their order of severity and with more than one expert opinion real life problems can be easily solved. The soft expert set along with the matrix models can be easily applied for any type of decision making problems.

\section{REFERENCES}

[1]. Alkhazaleh. S \& Salleh A.R, "Soft Expert Sets", Advances in Decision Sciences, (2011), Article ID 757868.

[2]. Chen.D "The Parameterization Reduction Of Soft Sets And Its Applications" Comput.Math.Appl.(2005),Volume 49,757-763.

[3]. Maji P. K. , Roy . A. R and Biswas. R "Fuzzy Soft Sets" Journal of Fuzzy Mathematics (2001), 9(3),589-602.

[4]. Maji. P. K , Biswas. R and Roy . A.R , "An application of soft sets in a decision making problem." Computers and Mathematics with Applications (2002), 1077-1083.

[5]. Maji. P. K , Biswas. R and Roy. A.R , "Soft Set Theory" Computers and Mathematics with Applications (2003), 555562.

[6]. Manash Jyoti Borah , Trdiv Jyoti Neog,Dusmanta Kumar Sut "Fuzzy Soft Matrix TheoryAnd Its Decision Making", IJMER Volume 2 , 121-127.

[7]. Maruah Bashir and Abdul Razak Salleh, "Fuzzy Parameterized Soft Expert Set" ( Research Article), Hindawi Publishing Corporation ,Abstract and Applied Analysis , , Article ID 258361, (2012) 
[8]. Molodtsov. D, "Soft Set Theory-First results”, Computers and Mathematics with Applications, (1999), 19-31

[9]. Pie. D, Miao . D "From Soft Sets to Information Systems" Granular Compute. IEEE Inter. Conf .2, (2005), 617-621

[10]. Rajarajeswari.P, Dhanalakshmi.P "Intuitionistic Fuzzy Soft Matrix Theory And Its Applications In Decision Making”, IJERT,(2013), Volume 2, 1100-1111.

[11]. Yong Yang and Chenli Ji., 2011 "Fuzzy soft matrices and their applications" LNAI 7002,618-627 